\title{
Diamonds Are a Publisher's Best Friend: The Baseball Mystique and Scholarly Publishing
}

\author{
by Steve Wilson
}

\section{7}

he publishing of sports books is a bit like a sport itself. Thriving on competition, it entails scorekeeping, stamina, learning on the run, a good sense of balance, the knack for working with forceful personalities, the will to succeed .... The analogy slows like the running back who realizes that he lost the ball twenty yards back. Those who succeed in sport have sculpted physiques, eight-figure contracts, and the adoration of millions, whereas the rewards of publishing books about them are, shall we say, subtler.

Sports publishing is at least as complex as the average sport, though, with even more layers and nuances. An astonishing range of books is written and published each year, covering all sports and serving all types of readers. Some are written for mass appeal, cashing in on an athlete's 15 minutes of fame, a game's peaking popularity, a current controversy. But many other sports books are out there, far from the bestseller lists yet warmly embraced by libraries and serious readers: sober for-all-time references, meticulous statistical compilations (sometimes setting out entirely new, intricately developed performance measurements), scholarly examinations of sport and culture, works of literature and criticism, photographic collections, painstakingly researched biographies and histories, instruction manuals, meandering recollections, and other categories too numerous to mention.
Baseball may no longer rank as the biggest spectator sport in the United States, but it still reigns in publishing. Many of the above book categories simply do not exist for other sports-care to name a penetrating analysis of the literature of hockey? A poignant collection of football poems? An alternative statistical ranking of soccer goalies? Consistently, writers and publishing executives extolling books on a trendy sport pause to admit that "baseball is still in first place,"1 "baseball is still king," ${ }^{2}$ or "baseball is by any yardstick the most popular sport of readers and book buyers." 3 It's almost too obvious to bother stating.

Numbers bear out such assertions. A search for "baseball" on Amazon.com in fall 2000 turned up 6,892 book listings; the nearest competitor*, football, had 5,060 , and no other sport came close: 3,366 hits for basketball, 3,296 for golf, 2,143 for soccer, 1,722 for hockey, 1,478 for tennis, and 134 for NASCAR. Similarly, an InfoTrac search for "baseball books" turned up 52 articles, while similar searches on other sports produced 28 golf articles, 10 tennis, 6 football, 5 basketball, 5

*Chess, though usually classified as a sport, deserves separate consideration and is not included here. soccer, 3 hockey, and 1 NASCAR. And interestingly, an InfoTrac search for "baseball" in the New York Review of Books scored 6 hits; of the other aforementioned sports, only soccer registered, with a single hit. This crude methodology cannot produce accurate data on any single sport, but to me it appears to indicate three things quite strongly: that more books are published about baseball than other sports; that baseball books are themselves written about more than their counterparts on other sports; and that baseball enjoys a unique perception of legitimacy as a serious subject. (Admittedly, thin evidence appears above for the last contention, but consider also that "Baseball and American Culture" is the subject of both an academic conference whose proceedings are published annually and a 4,500-entry bibliography published in $1995 .{ }^{4}$ In addition, the 896-page Cultural Encyclopedia of Baseball [McFarland, 1997] has been warmly received within and be- 
yond baseball fandom. Football fills more stadium seats these days, but what are its odds of exciting that kind of intellectual interest?)

\section{Special Fans of a Special Sport}

For most fans, one sport is special - perhaps it's basketball, for its unceasing motion, the beauty of unexpected arcs and fluidly moving bodies. Or football, for the power that is its hallmark. Or tennis, for the wits and finesse demanded. Or auto racing, for its thrilling speed, maintained over such time and distance as to lend a faintly epic quality.

Baseball, the true devotee will say, exhibits all of these qualities, and exceeds their sum. The krank (how many sports have a specially coined term for their fans - and one old enough to sound archaic, at that?) sees baseball not as a game, but, in a phrase familiar well beyond diamond fandom (though just short of Yale-Harvard), as The Game. To the fan, baseball becomes something more encompassing than a small-g game, more complex than a diversion, harder to know than a mere sport. To many Americans, the triumphs and failures of baseball's heroes connect with national character, the times of the country, the fiber of the populace; such is the power of names like Gehrig, DiMaggio, Robinson, McGwire, Ripken, and Rose. Herbert Hoover credited baseball with furnishing, next to religion, "a greater impact on American life than any other institution." 5 When the fortunes of the game itself take a dip, as they did during and after the 1994-1995 players' strike, cultural commentators write of the country's being out of kilter.

All this may say something meaningful about baseball itself, but that is (and has been, plentifully) a matter for discussion elsewhere. What it says about the baseball fan, not the game, is the thing that interests publishers - who, frankly speaking, are not always given to leisurely reflection upon the subjects they publish. To publishers, baseball

\section{To publishers, baseball} enthusiasts are a special breed: more single-minded than other sports fans, hungrier for minutiae, more conscious of their game's history and lore. enthusiasts are a special breed: more single-minded than other sports fans, hungrier for minutiae, more conscious of their game's history and lore. They tend to be lifelong followers of their sport, not trenders who may jump away when another game catches the public's fancy. They stay involved in their sport out of season. And they read books - or buy them anyway, which is all a publisher really requires: books of all kinds, year in, year out.

The experience of baseball fandom has even been the subject of books like psychologist William Freedman's More Than a Pastime: An Oral History of Baseball Fans (McFarland, 1998), in which fans of all ages "explain baseball's place in their lives and in the lives of the American people, their communities, and the nation." 6 It might not be accurate to say that baseball fans are as a group more contemplative than devotees of other sports (professional wrestling might be the exception, were it a sport), but it is hard to doubt that something in the nature of baseball tends to inspire introspection, reflection, aesthetic enjoyment - just what one often seeks in reading a book.

Is it the deliberate pace of the game, which allows action to be generously punctuated with moments of quiet drama? The complexity of baseball's rules, customs, language, history? Endless theories can be - have been - posited. Whatever the reason, baseball's faithful experience their game in a unique way.

Thus baseball fans will embrace books that would surely fail in other sports. True, the standard complement of athlete biographies and autobiographies ("Quick, get it on the shelves before he's arrested!" one can almost hear editors shouting), "success in life" books by winning managers ("Quick, before he's canned!"), and how-to manuals tend to bring in the big dollars, as in other sports. But baseball fandom has at its core enough truly devout students of the sport to support, at a far more modest sales level, a successful flow of books more specialized, more scholarly, more arcane than the mass market generally sees.

These books, from scholarly commercial publishers like McFarland (whose annual baseball list is largest at nearly two dozen titles), Greenwood, and Scarecrow, plus some univer- sity presses such as Nebraska, Southern Illinois, and Oxford, deliver the heavy factual detail, on mainly historical subjects, that only the fan of a certain scholarly bent wants. There are lots of Yankees followers around, for example, but it does take an uncommonly intense, longstanding interest to fork over $\$ 32.50$ for a 494-page book lavishly recounting only the team's season-opening games, as does New York Yankee Openers: An Opening Day History of Baseball's Most Famous Team, 1903-1996, by Lyle Spatz (McFarland, 1997) - a modestly profitable publication.

There is, of course, a great difference between a serious fan and a serious reader. One thing that distinguishes baseball, at least from unscientific observation, is the number of adherents who are serious on both counts. They're not even very hard to find, on the whole: often they are members of the Society for American Baseball Research (SABR), the preeminent organization of people who think hard about the game. SABR publishes books and journals, keeps track of current literature in the field, bestows research awards, holds an annual convention, and in many other ways mimics academic organizations. Its members are so immersed in the fabric of the game that they may care more about a pivotal 1904 game than last night's upset, and they are hungry to learn even more.

They also enjoy new ways of looking at their favorite subject. They sometimes reinvent statistics to reflect factors not accounted for in traditional measures; hence Bill James's term "sabermetrics," widely used since the 1980 s. They savor arguments over could-havebeens: What if Ted Williams hadn't lost five prime years to military service in two wars? What if the major leagues had opened the door to African Americans sooner? What if the 1919 World Series had not been fixed? Those are almost as good as arguments over the justice of selections for the Hall of Fame, the effects of interleague play, or the evils of artificial turf and the reserve clause. How better to while away the long winter months?

\section{Serving Up the Books}

McFarland, the company publishing the most baseball titles today (and, in the interest of fair disclosure, my employer), has drawn heavily on the SABR membership for both authors and customers. A strongly library-oriented publisher, McFarland brought out its first baseball titles in the mid-1980s, very much as an 
experiment. The early titles, marketed almost exclusively to libraries, were reference books, including a 22,000-entry bibliography.

They sold well enough to justify continuing and slightly broadening the experiment. Steady sales, more and more often coming from individuals, and an ever increasing flow of baseball manuscript proposals gave evidence that something good was in motion. Not only was a pool of highly capable authors chafing to be published, having been turned down in some cases by trade houses that deemed their works too specialized, but a market was waiting. Both libraries and the baseball cognoscenti wanted just this kind of book - the more specialized the better, it sometimes seemed.

Three parties with like interests had converged. McFarland was looking for fresh subjects and solid information rather than best seller flash, and the authors it published were not drawn by the bright lights of trade publishing. The sturdy, serious look of the books was no detriment to customers who welcomed what were often gap-filling works for their baseball collections. As McFarland's baseball list steadily gained mass and stature, it assumed an annually greater role in the company's output.

By the mid-1990s McFarland was publishing over a dozen baseball titles a year, ranging more widely in description. Unique reference works were always most desired, having generally the longest and most remunerative sales life, but statistical studies, league and team histories, interview books, topical stud-

\section{Baseball aficionados' liking for books may give print reference works a measure of protection well into the future.}

ies, and general histories plugged along soundly. Biographies were increasing in number and sales success. That pattern has continued to the present, with the annual list growing steadily. A brief look at the major types of baseball books that have succeeded for McFarland shows that baseball readers are a sophisticated audience with wide-ranging interests.

\section{Reference}

For a researcher or at-home baseball scholar, nothing is more welcome than a reference work collecting vast amounts of previously hard-to-find information in one place. Such books are sought by libraries and individuals alike, and publishers love them because they are high-dollar titles with long shelf lives. Books like The Baseball Encyclopedia and Total Baseball are perennially strong sell-
The future of the reference book, as electronic resources of various types become more ubiquitous, is the focus of much discussion at present. Baseball and other sports books are not immune from these concerns, but it is not clear how much damage Internet products will do them. A Publishers Weekly article in March 2000 addressed the electronic threat to sports books but drew no firm conclusion. Jeff Neuman, vice president and director of sports books at Simon \& Schuster, expressed pessimism, stating, "It is becoming increasingly difficult to publish the kind of popular sports reference books that used to do very well. I wonder if the generation that used to turn to books for popular reference now only associates reference with online and so the book is less popular." 8

Popular reference is a category apart from the more specialized, more expensive works that scholarly and reference publishers like McFarland produce. The reputation for unreliability that taints online resources in general may aid the prospects of print reference works. Buyer preferences are another powerful influence, aligned so far with books for the most part. As Lyons Press president Tony Lyons pointed out in the same Publishers Weekly article, "People love big, heavy reference books on subjects that they like." 9 Baseball aficionados' liking for books may give print reference works a measure of protection well into the future, given the undeniably superior aesthetic experience that a thick book, and its two supplements, by Myron J. Smith, Jr.; Ballparks of North America, by Michael Benson; The Cultural Encyclopedia of Baseball, by Jonathan Fraser Light; A Biographical Dictionary of the Baseball Hall of Fame, by John C. Skipper; and Baseball Records Registry: The Best and Worst Single-Day Performances and the Stories Behind Them, by Joseph J. Dittmar, are examples of reference books that have capitalized well on vacant niches.?

Authors who write or compile one reference book tend to return to reference for their following projects. Occasionally publishers even "convert" an author to reference works after a monograph or two, though most authors seem predisposed in one direction or the other.

\section{.}

.

\section{.}

.

\section{.}

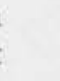
. 
devoted to great players whose names may be unfamiliar to the casual modernday fan, but hold magic for the SABR member or other enthusiast with a zest for the history of the game. Names like Honus Wagner, Rube Waddell, Jimmie Foxx, Mel Ott, Hack Wilson, and Al Lopez - remarkable players and personalities, not already written into the ground - are just the ticket for that audience.

\section{Team and League Histories}

The stories of prominent minor leagues, early major leagues, and individual teams are often ideal material for scholarly or enthusiast-oriented books. Large trade publishers ignore minor leagues especially, assuming the market to be too limited. A limited market is fine for a publisher like McFarland, if it is a welldefined market. Nineteenth-century baseball, for instance, is a hot research area for the SABR crowd, so McFarland is even receptive to histories of nineteenth-century teams: books on the New York Giants, 1870-1900, and the Cincinnati Red Stockings, $1869-1870$ (yes, two years!), have been low-key successes in recent years.

\section{Negro Leagues}

Baseball's dirtiest injustice, the exclusion of players of color from the established professional leagues until midway through the twentieth century, gave rise to a parallel game that built a rich history of its own. Largely overlooked until the last few decades, Black baseball is an irresistible subject for many students of the game today. That it produced players whose talent equaled or surpassed the top White players of the day is incontrovertible; the effect of these players' absence from the game as it developed into America's national pastime is impossible to estimate. Many books have been published on Black baseball since the 1970 s (by both trade and scholarly publishers) and many more remain to be written, though unfortunately researchers are limited by the lack of full and rigorous statistical records and by spotty contemporary reportage. The tantalizing air of mystery that has resulted will keep the appetite for information strong.

\section{Local Interest}

What baseball fan is not interested in how the game has been played close to home, wherever that may be? North Carolina has a strong baseball heritage, and as a North Carolina publisher, McFarland has been lucky to receive some very strong manuscripts about Tar Heel baseball. Two popular titles are Pro- fessional Baseball in North Carolina: An Illustrated City-by-City History, 19011996, by J. Chris Holaday, and The Independent Carolina Baseball League, 19361938: Baseball Outlaws, by R.G. (Hank) Utley and Scott Verner. Also close to home is Textile League Baseball: South Carolina's Mill Teams, 1880-1955, by Thomas K. Perry. ${ }^{10}$ The market for such books is by no means exclusively local, but the interest they stir up at home is very strong. Everyone feels proprietary about the home team, after all.

\section{Literature}

No survey of this kind would be complete without mentioning a category in which baseball stands almost alone among sports. Widely considered the most aesthetically involving of modern sports, baseball has inspired a large body of literature, including novels, short stories and poetry (even McFarland, a nonfiction publisher, has issued several volumes of baseball poetry). George Plimpton has famously suggested that the quality of literary sports writing is inversely proportional to the size of the ball $^{11}$ - apparently setting the stage for the great table tennis novel or golf bildungsroman, but in fact extolling baseball literature. Sports fiction is a subject for separate study, however.

\section{Will Baseball Be Dethroned?}

Though its supremacy among sports as a publishing subject is longstanding and universally acknowledged, wavering only in rare lean years such as followed the strike of the mid-1990s, baseball is not the top spectator sport in the United States today, having been displaced by football long ago. Football is published fairly heavily by trade houses, but it is not generally regarded as a cultural phenomenon worthy of serious study and has not been a strong subject for scholarly publishers.

The hot rising sport for trade publishing in the last decade or so - even before Tiger Woods - has been golf. Oddly enough, golf writing has been likened to baseball writing, as in a 1997 Publishers Weekly report on sports publishing:

The one positive thing that golf has learned from baseball is that it is developing a literature of its own. 'Golf writers' commentaries are more reflective to begin with because the game is not an exciting game, per se,' says Bantam's [editor Brian] Tart. 'So you ruminate a lot more if you're a golf writer, and you do if you're a baseball writer too. If you're a football writer it's all action. Golf is a relationship game. ${ }^{12}$

An unusual aspect of golf as a publishing subject is that a great many of its followers actually participate in the sport; in fact, as sportswriter Roger Kahn has said, it is a sport "best played, not watched." 13 The experiential bond thus formed surely boosts the popularity of some types of golf books, but it has no clear impact on scholarly or reference titles. Despite a furious period of golf publishing, during which there has been "no more profitable area of sports publishing,"14 a Booklist "Spotlight on Sports" wrap-up of reference sources in September 2000 concluded that "Golf reference works are a little thin." 15 Without a substantial body of references, player biographies, and other serious works, golf will not approach baseball's status in print.

Another sport inspiring much publishing activity of late is stock car racing (generally referred to simply as NASCAR). Surprisingly, NASCAR has also been compared seriously to baseball:

'NASCAR is like baseball,' says Scott Huler, author of A Little Bit Sideways: One Week Inside a NASCAR Winston Cup Race Team (MBI, \$14.95). 'It's a sport that completely supports a literature. It has the same rhythms as baseball: a long, slow contest, little tiny adjustments, and suddenly they have a profound effect and so reward concentration and people with a long attention span. NASCAR right now is like baseball 100 years ago.' 16

The comparison may be a bit farfetched, but NASCAR's popularity is indisputable. Whether that will translate into the kind of multifaceted, fiercely devoted book audience that baseball has long attracted cannot be predicted at this early date.

\section{Conclusion}

If any proof of baseball's unique stature in publishing were needed, comparisons like those above tell the story. To make an argument for another sport's book prospects, standard practice is to explain how it is "just like baseball." But baseball is one of a kind. No other sport in America has its enduring appeal, its power to inspire artful reflection, its impact on society. Popular publications will always reflect ephemeral trends, but among a serious readership baseball's pull is unfaltering. 


\section{References}

${ }^{1}$ Dermot McEvoy, "A New Player Roars Onto the Sports Scene," Publishers Weekly 246:12 (March 22, 1999): 54.

${ }^{2}$ Ibid.

${ }^{3}$ Keith Dawson, "Playing Ball with Books: Publishers in the Spectator Sport Arena Find Celebrity and Team Titles Are a Gamble, but Statistics Are a Sure Bet," Publishers Weekly 237:7 (Feb. 16, 1990): 23.

${ }^{4}$ The annual conference proceedings, since 1997, are published in Alvin L. Hall, series ed., The Cooperstown Symposium on Baseball and American Culture (Jefferson, N.C.: McFarland, 2000- ). Addressing the same topic is Donald E.
Walker, and B. Lee Cooper, compilers, Baseball and American Culture: A Thematic Bibliography of Over 4,500 Works (Jefferson, N.C.: McFarland, 1995).

${ }^{5}$ David H. Nathan, ed. The McFarland Baseball Quotations Dictionary (Jefferson, NC: McFarland, 2000), 194.

${ }^{6}$ G.S. Rowe, Untitled review, Nine: A Journal of Baseball History and Social Policy Perspectives, vol. 8 (Fall 1999): 65.

${ }^{7}$ The Baseball Encyclopedia: The Complete and Definitive Record of Major League Baseball, 10th ed. (New York: Macmillan, 1996); John Thorn, Pete Palmer, Michael Gershman, and David Pietrusza, eds., Total Baseball: The Official Encyclopedia of Major League Baseball, 6th ed. (New York: Total Sports, Inc., 1999); Myron J. Smith,
Jr., Baseball: A Comprehensive Bibliography (Jefferson, N.C.: McFarland, 1986); Baseball: A Comprehensive Bibliography, Supplement 1 (1985-May 1992) Jefferson, N.C.: McFarland, 1993); Baseball: A Comprehensive Bibliography, Supplement 2 (1992 through 1997), (Jefferson, N.C.: McFarland, 1998); Michael Benson, Ballparks of North America: A Comprehensive Historical Reference to Baseball Grounds, Yards and Stadiums, 1845 to Present (Jefferson, N.C.: McFarland, 1989); Jonathan Fraser Light, The Cultural Encyclopedia of Baseball (Jefferson, N.C.: McFarland, 1997); John C. Skipper, A Biographical Dictionary of the Baseball Hall of Fame (Jefferson, N.C.: McFarland, 2000); Joseph J. Dittmar, Baseball Records Registry: The Best and Worst Single-Day Performances and the Stories Behind Them (Jefferson, N.C.: McFarland, 1997).

${ }^{8}$ Dermot McEvoy, "Hitting to All Fields: Sports Publishing Brings Its Game to New Categories and New Markets," Publishers Weekly 247:12 (March 20, 2000): 59 .

${ }^{9}$ Ibid.

$10 \mathrm{~J}$. Chris Holaday, Professional Baseball in North Carolina: An Illustrated Cityby-City History, 1901-1996 (Jefferson, N.C.: McFarland, 1998); R.G. (Hank) Utley, and Scott Verner, The Independent Carolina Baseball League, 1936-1938: Baseball Outlaws Jefferson, N.C.: McFarland, 1999; Thomas K. Perry, Textile League Baseball: South Carolina's Mill Teams, 1880-1955 (Jefferson, N.C.: McFarland, 1993).

${ }^{11}$ George Plimpton, "The Smaller the Ball, the Better the Book: A Game Theory of Literature," New York Times Book Review, May 31, 1992: 16.

12 Dermot McEvoy, "As Baseball Fades, Golf Puts a Tiger in Its Tank," Publishers Weekly 244:14 (April 7, 1997): 38.

${ }^{13}$ David H. Nathan, The McFarland Baseball Quotations Dictionary (Jefferson, N.C.: McFarland, 2000), 113.

14 Dermot McEvoy, "Hitting to All Fields: Sports Publishing Brings Its Game to New Categories and New Markets," Publishers Weekly 247:12 (March 20, 2000): 52.

15 Don Maxwell, "Reference Sources on Sports," Booklist 97:1 (Sept. 1, 2000): 171.

${ }^{16}$ Dermot McEvoy, "A New Player Roars Onto the Sports Scene," Publishers Weekly 246:12 (March 22, 1999): 54.

McFarland's baseball books may be found on the Web site <www.mcfarlandbaseball.com>. Print catalogs are also available by phone $(800$ 253-2187), e-mail (info@mcfarlandpub.com) or mail-in request: McFarland \& Company, Inc., Publishers, Box 611, Jefferson NC 28640. 